\title{
High-Flow Nasal Cannula for Neonatal Respiratory Distress: Is It Enough?
}

CPAP is the most studied form of noninvasive ventilation in neonates, and early investigations focused on the use of CPAP following surfactant administration, to minimize the need for invasive mechanical ventilation. ${ }^{1}$ Verder and colleagues demonstrated that a strategy of CPAP following brief intubation and surfactant administration (the INSURE technique: INtubation, SURfactant, Extubation) improved outcomes in patients with respiratory distress syndrome (RDS), ${ }^{2}$ and those results were replicated in multiple randomized controlled trials. ${ }^{3}$ In addition, early observational studies also suggested that preterm neonates treated with CPAP alone (without endotracheal intubation and surfactant) had less need for mechanical ventilation. ${ }^{4-8}$ The Neonatal Research Network's SUPPORT (Surfactant, Positive Pressure, and Pulse Oximetry Randomized Trial) trial in extremely preterm infants confirmed that CPAP alone was superior to intubation and surfactant administration within 1 hour of birth. ${ }^{9}$ Those results, along with similar findings from the European CURPAP study, led to the general acceptance of CPAP as an alternative to intubation and surfactant administration in extremely preterm neonates. ${ }^{10}$

Despite these recognized benefits of CPAP, the optimal method for the noninvasive delivery of distending pressure is unknown. A variety of devices are currently utilized, and they differ in both the type of gas flow generated (constant vs variable flow) and patient interface. ${ }^{11}$ Regardless of the interface selected, nasal breakdown is a frequent complication associated with all infant nasal CPAP devices. ${ }^{12}$ In one study, $13 \%$ of infants treated with CPAP developed some form of nasal complication after only 10 days of support. ${ }^{13}$ These complications include skin excoriation, nasal damage, nasal obstruction, and cutaneous infection. ${ }^{14}$

\section{See the Original Study on Page 1893}

Concern regarding these complications has prompted clinicians and investigators to search for less invasive ways to provide respiratory support for neonates, and there has recently been a growing interest in the use of high-flow nasal cannula (HFNC) as a mechanism to provide continuous distending pressure to neonates with RDS. ${ }^{15,16} \mathrm{Nu}-$ merous studies have demonstrated the safety of HFNC in neonates, ${ }^{17}$ but the amount of pressure actually provided by these devices remains in question. ${ }^{18,19}$
In this issue of Respiratory CARE, Volsko et al further elucidate the issue of continuous distending pressure generation by HFNC. ${ }^{20}$ In their bench study, the nasal cannulae were optimally sized to models of premature, infant, and pediatric nares. Pressure changes, mean airway pressure, and tidal volume were then measured at HFNC flows of 2-6 L/min and simulated respiratory muscle use. Volsko et al concluded that, in their experimental model of appropriately fitted nasal cannulae, flows of 2-6 L/min did not generate clinically important positive airway pressure.

Volsko's results contradict the 15-year-old finding of Locke et al, that a flow of $2 \mathrm{~L} / \mathrm{min}$ provides a positive continuous distending pressure in neonates. ${ }^{21} \mathrm{~A}$ similar rise in continuous distending pressure was found by Sreenan and colleagues, using HFNC in premature infants with apnea. They found that HFNC could deliver continuous distending pressure similar to nasal CPAP and that the amount of flow necessary to create continuous distending pressure increased linearly with the infant's weight. ${ }^{22}$ However, more recent studies of pharyngeal pressure in infants on HFNC found that continuous distending pressure increased only at flows $>4 \mathrm{~L} / \mathrm{min}^{23,24}$

Despite the data that HFNC creates continuous distending pressure, clinical trials of HFNC in neonatal RDS have been inconclusive. A randomized trial of nasal CPAP versus HFNC in preterm infants immediately following extubation found a significantly higher rate of re-intubation in the HFNC group. ${ }^{18}$ Nair compared humidified HFNC to CPAP in preterm infants with RDS, within 6 hours of birth, and found similar rates of re-intubation and duration of respiratory support in the groups, but that study was terminated early due to the recall of the HFNC device utilized. ${ }^{25}$ While these clinical investigations did not specifically record the amount of continuous distending pressure delivered by the HFNC devices, the inconsistent clinical benefit suggests that the continuous distending pressure was variable or inadequate.

This inconsistency of continuous distending pressure with HFNC was confirmed by Lampland and colleagues in a combined in vitro and in vivo study. They used expiratory esophageal pressure as a measure of continuous distending pressure, and found a wide inter-patient and intra-patient range of pressures at all HFNC flows tested. ${ }^{23}$ Patient weight is an- 
other important determinant of continuous distending pressure variability, as demonstrated by Sreenan et al. ${ }^{22}$ In addition, volume and pressure loss through the open mouth impacts the effectiveness of continuous distending pressure from HFNC. Kubicka et al found that mouth closure was necessary to achieve a linear relationship between flow rate and delivered continuous distending pressure. ${ }^{26}$

Volsko et al ${ }^{20}$ address the issue of the cannula's inner diameter as an important source of variability in the continuous distending pressure. Prior to this investigation, limited data existed regarding the impact of cannula inner diameter on continuous distending pressure variability. ${ }^{24}$ The results from Volsko et al are consistent with previous data that, even when the inner diameter of the nasal cannula is optimally fit, reliable continuous distending pressure is not achieved at flows between $2 \mathrm{~L} / \mathrm{min}$ and $6 \mathrm{~L} /$ min. ${ }^{27}$ This lack of appreciable continuous distending pressure from HFNC in a bench model, along with the growing number of negative clinical investigations, continues to bring into question the clinical impact of HFNC in the setting of neonatal RDS. 18,28,29

It is essential to remember that not all infants can be successfully supported with CPAP alone, as demonstrated by the high rates of intubation in the CPAP-only arms of the SUPPORT and the CURPAP trials, and that the optimal strategy of respiratory support in neonates remains elusive. ${ }^{30}$ Randomized clinical trials are needed to identify which patients are most likely to benefit from noninvasive ventilation and the optimal devices to deliver that support. ${ }^{24}$ In the meantime, carefully designed experimental studies such as the one by Volsko and colleagues are important additions to the body of available data addressing the effectiveness of HFNC in delivering continuous distending pressure. Contributions of this nature are essential, not only for the design of future randomized trials, but also to assist clinicians in their current decision making at the bedside. While the movement toward less invasive therapies to support neonates with RDS is laudable, a firm recommendation for or against HFNC as an alternative to nasal CPAP will have to await the results of a randomized controlled trial that directly compares these 2 therapies.

\section{Christoph P Hornik MD David A Turner MD}

Division of Pediatric Critical Care Medicine Department of Pediatrics Duke University Medical Center Durham, North Carolina

\section{REFERENCES}

1. Mahmoud RA, Roehr CC, Schmalisch G. Current methods of noninvasive ventilatory support for neonates. Paediatr Respir Rev 2011; 12(3):196-205.
2. Verder H, Robertson B, Greisen G, Ebbesen F, Albertsen P, Lundstrom K, et al. Surfactant therapy and nasal continuous positive airway pressure for newborns with respiratory distress syndrome. Danish-Swedish Multicenter Study Group. N Engl J Med 1994; 331(16):1051-1055.

3. Stevens TP, Harrington EW, Blennow M, Soll RF. Early surfactant administration with brief ventilation vs. selective surfactant and continued mechanical ventilation for preterm infants with or at risk for respiratory distress syndrome. Cochrane Database Syst Rev 2007(4): CD003063.

4. Avery ME, Tooley WH, Keller JB, Hurd SS, Bryan MH, Cotton RB, et al. Is chronic lung disease in low birth weight infants preventable? A survey of eight centers. Pediatrics 1987;79(1):26-30.

5. Van Marter LJ, Allred EN, Pagano M, Sanocka U, Parad R, Moore $\mathrm{M}$, et al. Do clinical markers of barotrauma and oxygen toxicity explain interhospital variation in rates of chronic lung disease? The Neonatology Committee for the Developmental Network. Pediatrics 2000;105(6):1194-1201.

6. Vanpee M, Walfridsson-Schultz U, Katz-Salamon M, Zupancic JA, Pursley D, Jonsson B. Resuscitation and ventilation strategies for extremely preterm infants: a comparison study between two neonatal centers in Boston and Stockholm. Acta Paediatr 2007;96(1):10-16; discussion 18-19.

7. Gittermann MK, Fusch C, Gittermann AR, Regazzoni BM, Moessinger AC. Early nasal continuous positive airway pressure treatment reduces the need for intubation in very low birth weight infants. Eur J Pediatr 1997;156(5):384-388.

8. Poets CF, Sens B. Changes in intubation rates and outcome of very low birth weight infants: a population-based study. Pediatrics 1996; 98(1):24-27.

9. Finer NN, Carlo WA, Walsh MC, Rich W, Gantz MG, Laptook AR, et al. Early CPAP versus surfactant in extremely preterm infants. N Engl J Med 2010;362(21):1970-1979.

10. Sandri F, Plavka R, Ancora G, Simeoni U, Stranak Z, Martinelli S, et al. Prophylactic or early selective surfactant combined with nCPAP in very preterm infants. Pediatrics 2010;125(6):e1402-1409.

11. Roehr CC, Schmalisch G, Khakban A, Proquitte H, Wauer RR. Use of continuous positive airway pressure (CPAP) in neonatal units-a survey of current preferences and practice in Germany. Eur J Med Res 2007;12(4):139-144.

12. Morley C, Davis P. Continuous positive airway pressure: current controversies. Curr Opin Pediatr 2004;16(2):141-145.

13. Jatana KR, Oplatek A, Stein M, Phillips G, Kang DR, Elmaraghy CA. Effects of nasal continuous positive airway pressure and cannula use in the neonatal intensive care unit setting. Arch Otolaryngol Head Neck Surg 2010;136(3):287-291.

14. Yong SC, Chen SJ, Boo NY. Incidence of nasal trauma associated with nasal prong versus nasal mask during continuous positive airway pressure treatment in very low birthweight infants: a randomised control study. Arch Dis Child Fetal Neonatal Ed 2005;90(6):F480F483.

15. Spence KL, Murphy D, Kilian C, McGonigle R, Kilani RA. Highflow nasal cannula as a device to provide continuous positive airway pressure in infants. J Perinatol 2007;27(12):772-775.

16. Quinn. Nasal cannula treatment for apnea of prematurity. PAS 2005; 57:1248-1252.

17. DiBlasi RM. Nasal continuous positive airway pressure (CPAP) for the respiratory care of the newborn infant. Respir Care 2009;54(9): 1209-1235.

18. Campbell DM, Shah PS, Shah V, Kelly EN. Nasal continuous positive airway pressure from high flow cannula versus Infant Flow for Preterm infants. J Perinatol 2006;26(9):546-549.

19. Jasin LR, Kern S, Thompson S, Walter C, Rone JM, Yohannan MD. Subcutaneous scalp emphysema, pneumo-orbitis and pneumocepha- 


\section{High-Flow Nasal Cannula for Neonatal Respiratory Distress: Is It Enough?}

lus in a neonate on high humidity high flow nasal cannula. J Perinatol 2008;28(11):779-781.

20. Volsko TA, Fedor K, Amadei J, Chatburn RL. High flow through a nasal cannula and CPAP effect in a simulated infant model. Respir Care 2011;56(12):1893-1900.

21. Locke RG, Wolfson MR, Shaffer TH, Rubenstein SD, Greenspan JS. Inadvertent administration of positive end-distending pressure during nasal cannula flow. Pediatrics 1993;91(1):135-138.

22. Sreenan C, Lemke RP, Hudson-Mason A, Osiovich H. High-flow nasal cannulae in the management of apnea of prematurity: a comparison with conventional nasal continuous positive airway pressure. Pediatrics 2001;107(5):1081-1083.

23. Lampland AL, Plumm B, Meyers PA, Worwa CT, Mammel MC. Observational study of humidified high-flow nasal cannula com-

The authors have disclosed no conflicts of interest.

Correspondence: David A Turner MD, Division of Pediatric Critical Care, Department of Pediatrics, Duke University Medical Center, Box 3046, Durham NC 27710. E-mail: david.turner@duke.edu.

DOI: $10.4187 /$ respcare. 01645 pared with nasal continuous positive airway pressure. J Pediatr 2009; 154(2):177-182.

24. Wilkinson D, Andersen C, O'Donnell CP, De Paoli AG. High flow nasal cannula for respiratory support in preterm infants. Cochrane Database Syst Rev 2011(5):CD006405.

25. Nair GKP. Comparison of the effects of Vapotherm and nasal CPAP in respiratory distress. Pediatr Acad Soc 2005;57:2054.

26. Kubicka ZJ, Limauro J, Darnall RA. Heated, humidified high-flow nasal cannula therapy: yet another way to deliver continuous positive airway pressure? Pediatrics 2008;121(1):82-88.

27. Ovalle OGT, Troncoso C, Palacios J, Ortiz E. High flow nasal cannula after surfactant treatment for infant respiratory distress syndrome in perterm infants 30 weeks. PAS 2005;57:3417-3423.

28. Shoemaker MT, Pierce MR, Yoder BA, DiGeronimo RJ. High flow nasal cannula versus nasal CPAP for neonatal respiratory disease: a retrospective study. J Perinatol 2007;27(2):85-91.

29. Courtney SE, Pyon KH, Saslow JG, Arnold GK, Pandit PB, Habib RH. Lung recruitment and breathing pattern during variable versus continuous flow nasal continuous positive airway pressure in premature infants: an evaluation of three devices. Pediatrics 2001;107(2): 304-308.

30. DiBlasi RM. Neonatal noninvasive ventilation techniques: do we really need to intubate? Respir Care 2011;56(9):1273-1296. 